\title{
Analysis of Secondary Metabolites as Potential Phytoalexins, Their Secretion Sites and Proposed Resistance Markers to Vascular Streak Dieback in Theobroma cacao $\mathbf{L}$.
}

\author{
Teguh Iman Santoso ${ }^{1 *}$, M. Miftahudin ${ }^{2)}$, Yohana C. Sulistyaningsih' ${ }^{2)}$ and Suryo Wiyono ${ }^{3)}$ \\ ${ }^{1)}$ Indonesian Coffee and Cocoa Research Institute, Jl. PB. Sudirman 90, Jember, Indonesia. \\ ${ }^{2}$ Department of Biology, Faculty of Mathematics and Natural Sciences, Bogor Agricultural University, Bogor, Indonesia. \\ ${ }^{3}$ Department of Plant Protection, Faculty of Agriculture, Bogor Agricultural University, Bogor, Indonesia. \\ *) Corresponding author: tisantoso.iccri@gmail.com
}

\begin{abstract}
Study on resistance mechanism to vascular-streak dieback (VSD) disease in cacao (Theobroma cacao L.) is limited due to the lack of fungal spores for artificial inoculation. This research was conducted to study the production of secondary metabolites that appear to be evidence of defense signaling in resistant clone of Sca 6 and susceptible clone of TSH 858 to Ceratobasidium theobromae natural infection. A fungal staining method was employed to detect C. theobromae hyphae at early infection stages, before VSD symptoms appear. Metabolite profiling was analyzed using pyrolysis gas chromatography mass spectrometry (Py-GCMS) at pre-, early and late stages of C. theobromae infection. Histochemical and anatomical characteristics of both healthy and infected leaves were also observed to identify the accumulation sites of secondary metabolites on and in cocoa leaf tissues. The results confirmed that fungal staining using trypan blue can detect early stages of $C$. theobromae infection; at the $14^{\text {th }}$ week (on susceptible seedlings) and the $18^{\text {th }}$ week (on resistant clones), following placement of the seedlings under infected cacao plants. Phenylpropanoid biosynthesis, terpenoid biosynthesis, environmental information processing signal transduction pathways, and aromatic biodegradation were detected as important metabolite pathways during defense mechanism. I-limonene (terpenoid), p-ethylguaiacol (phenols) and 2.3 dihidrobenzofuran (heterocyclic compounds) were proposed as an active defense produced by the host after infected by pathogen mainly on late infection of $C$. theobromae. Terpenoid and phenol compounds were accumulated on the glandular trichomes, idioblast of upper and bottom epidermis, phloem vessel and cortex idioblast of cacao leaves. Epidermis thickness of resistant clone was significantly greater than that of susceptible clone on both surfaces. Leaf epidermis tissue and the accumulated compounds in epidermis idioblast may act as the physical and biochemical markers of cocoa resistance to VSD.
\end{abstract}

Keywords: Theobroma cacao, fungal staining, histochemical, Py-GCMS, resistances, VSD

\section{INTRODUCTION}

Vascular streak dieback (VSD) is a major constraint of cacao (Theobroma cacao L.) production in Southeast Asia and Melanesia
(Samuel et al., 2012). In Southeast Asian countries, which include Indonesia as the world third largest cocoa producer (ICCO, 2014), VSD caused $40-60 \%$ losses of the national cacao production. The occurrence 
of VSD had been firstly reported in Papua New Guinea (PNG), and the disease had expanded northwestward to Kerala State in India, and Hainan Island, the southernmost of China (Keane \& Prior, 1991). Wind-dispersed basidiospores of $C$. theobromae are released during periods of continously heavy rainfall and high humidity. After penetrating cacao leaf, the fungal hyphae colonize xylem vessels, causing browning of the veins of lamina; which spreads to leaf midrib and petioles, and eventually reaches the branch. Colonization by $C$. theobromae is found only in the xylem vessels of cacao (Talbot \& Keane, 1971); as a characteristic that distinguishes it from other diseases caused by fungi in cacao (Samuel et al., 2012). The recognizable symptoms of VSD include chlorosis of the leaves, with scattered spots on the lamina remaining green (Guest \& Keane, 2007).

VSD was caused by the basidiomycete fungus of $C$. theobromae, which is a member of the genus Ceratobasidium (Talbot \& Keane, 1971). This fungus is an obligate parasite and cannot be grown in pure culture. The only experiment that successfully induced the sexual stage of the fungus was conducted in Malaysia using solid Corticium culture media (CCM) and liquid coconut water media, incubated at $25^{\circ} \mathrm{C}$ under 10/14 hours of light/ dark (Lam et al., 1988), but this experiment could not be repeated in PNG (Dennis, 1991). Therefore, the challenge is to study the plant response to the fungus without the option of artificial inoculation.

Cacao resistance mechanism in response to $C$. theobromae infection is still unclear. Resistance evaluation and selection of plants for evaluation can only be done in a VSD epidemic area due to the lack of spores that could be used for artificial inoculation (Guest \& Keane, 2007). The resistance response to VSD varies among cacao clones.
Halimah \& Sri-Sukamto (2007) classified some cacao clones of Sulawesi 1, Sulawesi 2, and Sca 6 as VSD-resistant, based on a VSD-symptom-scoring method; whereas other cacao clones of ICS 60 and TSH 858, were classified as VSD-susceptible (Susilo \& Anita-Sari, 2009). Other potentially VSDresistant clones of DRC 15, KA 2-10 and VSD2Ldg were also found in Sulawesi (McMahon et al., 2010).

The epidemiology of VSD is controlled by a strong association between the fungus survival and environmental factors, and therefore it is necessary to study the host response to $C$. theobromae infection under natural conditions. However, it is difficult to determine early infection by $C$. theobromae based on obvious VSD symptoms. Histochemical staining of $C$. theobromae hyphae from infected leaves can be used to detect the presence of the fungus during early natural infection. The presence of $C$. theobromae hyphae may also be an indication of secondary metabolite production; which acting as phytoalexins, in response to defense signaling as part of cocoa resistance mechanism response to the pathogen.

The objectives of the research were to analyze profiles of secondary metabolites produced by $C$. theobromae-infected cacao leaves, to identify secondary metabolite production sites in the infected leaf tissues, and to identify any leaf anatomical differences as characteristics of VSD-resistant and VSDsusceptible cacao clones. This paper reported the secondary metabolites produced during C. theobromae infection may be as phytoalexins, histochemical analysis of secondary metabolite accumulation in leaf tissues, and leaf anatomical data. Information gathered from this study can be used for pathogenesis studies and selection tools to support breeding and development of VSD-resistant cacao. 


\section{MATERIALS AND METHODS}

Two cacao clones, i.e. Sca 6 (resistant) and TSH-858 (susceptible) were used in the experiment. Seven-month-old seedlings propagated through top grafting, were grown in and outside VSD epidemic area.

The study was conducted in a VSD epidemic area, Kaliwining Experimental Station of Indonesian Coffee and Cacao Research Institute (ICCRI), Jember, Indonesia. Histo-chemical and anatomical analyses were carried out in Microtechnique Laboratory, Department of Biology, Bogor Agricultural University, Bogor, Indonesia. Secondary metabolite analysis using pyrolysis gas chromatography mass spectrometry (Py-GCMS) was carried out at the Chemical and Proximate Integrated Laboratory, Forestry Research and Development Center, Gunung Batu, Bogor, Indonesia.

The experiment used a randomized complete block design in factorial with three replications. The first factor was two cacao clones, i.e. VSD-resistant (Sca 6) and VSDsusceptible (TSH 858). The second factor was two VSD infection treatments, i.e. naturally VSD-infected cacao seedlings, placed under infected cacao trees, and non-infected cacao seedlings, placed outside the area of cacao plants at a distance of approximately $3000 \mathrm{~m}$. Observation for the presence of $C$. theobromae infection and VSD symptoms was performed every two weeks using three plant samples per experimental unit. Metabolite profiling was carried out at pre-, early and late infection stages using three biological replications with two technical replications per biological replication. Phenolic, terpenoid and alkaloid histochemical staining was done using three biological replications with five observation views per replication.

Pre-infection is the pre-exposure condition, one day before seedlings are placed under infected plants, and when neither $C$. theobromae nor VSD symptoms have yet been detected. Early infection is defined as the first time C. theobromae hyphae have been detected in the xylem vessel of the infected leaf, but VSD symptoms have not yet appeared. Late infection is the condition when both C. theobromae and VSD symptoms have been detected.

The presence of $C$. theobromae hyphae was checked every two weeks using a fungal staining method based on Liberato et al. (2005). Leaf midrib samples (lamina containing midrib) of $1 \mathrm{~cm}^{2}$ were soaked in a $20 \mathrm{~mL}$ $1: 1(\mathrm{v} / \mathrm{v})$ solution of glacial acetic acid and absolute ethanol in a closed container at room temperature for 24 hours. Leaf samples were cross-sectioned using a razor blade, then mounted on glass slide and given a drop of $85 \%$ lactic acid and $0.1 \%$ trypan blue. Any presence of the fungus was observed under light microscope Olympus CX21 (Olympus, Japan), and identified using species description of $C$. theobromae as done by Junianto \& Sri-Sukamto (1986). The hyphae of C. theobromae are typically characterized by right-angle branching, and colonize only xylem vessels of cacao.

Secondary metabolite profiles were identified using a Shimadzu QP2010 (Shimadzu, Japan) Pyrolysis GCMS, and the sample preparation method was based on Chaves \& Gianfagna (2007). Leaf samples were homogenized using a pestle and mortar, and a $0.002 \mathrm{~g}$ homogenized sample was then put into the GCMS instrument. The chemical components of the sample were identified under the following settings/conditions: pyrolysis temperature at $400^{\circ} \mathrm{C}$; $\mathrm{GC}$ oven temperature at $50^{\circ} \mathrm{C}$; injector temperature at $280^{\circ} \mathrm{C}$; and interface temperature ion source at $280^{\circ} \mathrm{C}$. Helium gas was used as the carrier.

The mass spectrograms were identified by matching them against those from the existing mass spectrum database provided 
in the GCMS instrument, which cross-refers to the National Institute of Standard and Technology (NIST) Library, Maryland, USA. Analysis of peak area chromatogram data was performed using the One-Way Analisis of variance (Anova) and Tukey test at $5 \%$ of confidencial level. The types of metabolite were identified using the PubChem (http://pubchem.ncbi.nlm. nih.gov/) database. Metabolite pathways were developed using the pathway maps of the KEGG database (http://www.genome.jp/kegg/pathway).

Metabolite accumulation sites on and in leaf tissues were identified by histochemical test. The leaf used for sampling in the analysis was the sixth leaf back from the tip in each case. Fresh samples were cross-sectioned using a freezing microtome: a Yamato RV-240 (Yamato Kohki Ind Co, Japan) with $30 \mu \mathrm{m}$ razor-blade thickness. Terpenoids were identified using 5\% copper acetate, following a procedure suggested by Harborne (1987); phenolic compounds were identified using a $5 \%$ ferric trichloride procedure suggested by Johansen (1940). Anatomical characteristics of the cacao leaf were also investigated, based on both transversal and paradermal sections. Samples were fixed in $70 \%$ alcohol, and then cross-sectioned using a freezing microtome: a Yamato RV-240 (Yamato Kohki Ind Co, Japan) in $20 \mu \mathrm{m}$ thickness. Paradermal sections of each leaf were prepared as semipermanent samples using a whole-mount method first suggested by SASS (1951). The alcohol-fixed leaves were rinsed with distilled water and soaked in 50\% nitric acid solution, before being rinsed again with distilled water three times. Adaxial and abaxial surface layers of leaves were peeled using a razor blade. Samples were observed under an Olympus CX-21 light microscope (Olympus, Japan), and photographed using an Optilab Advance camera (Miconos, Indonesia). Measurement of anatomical characteristics, i.e. epidermis thickness, stomatal size, stomatal density, stomatal index, palisade thickness, glandular trichome density, glandular trichome length and glandular trichome width, was performed using Image Raster Software (Miconos, Indonesia). Stomatal index was measured based on number of epidermis divided by number of stomata.

\section{RESULTS AND DISCUSSION}

Plant disease resistance mechanisms involve activation of a series of defense pathways as part of the defense mechanism against pathogen attack. Plants have a regulatory mechanism to activate particular defense responses according to the specific stimuli received (Chaves \& Gianfagna, 2007). Phytoalexin is a chemically diverse group of secondary metabolites with strong antimicrobial actions, and these metabolites accumulate around the infection site. They are generally undetectable in the plant before infection, but are synthesized very rapidly after pathogen attack (Taiz \& Zeiger, 2010).

Fungal staining successfully detected the early infection stage of $C$. theobromae in VSD-susceptible and VSD-resistant plants, at the $14^{\text {th }}$ and $18^{\text {th }}$ weeks, respectively, after cacao seedlings had been placed under VSDinfected cacao plants. Susceptible clone (TSH 858) was infected faster than resistant clones (Sca 6). Although the hyphae had been detected in the xylem vessels, the leaves appeared normal and healthy, exhibiting no visible symptoms of VSD (Figure $1 \& 2$ ). The VSD symptoms of leaves used in this study were interpreted according to observed leaf chlorosis with green spots, as described by Guest \& Keane (2007).

During onset of $C$. theobromae infection, cacao leaves produced 20 different metabolites. Chromatogram areas from Py-GCMS analysis of both VSD-resistant (Sca 6) and VSD-susceptible clones (TSH 858) were not statistically different at the pre-infection 

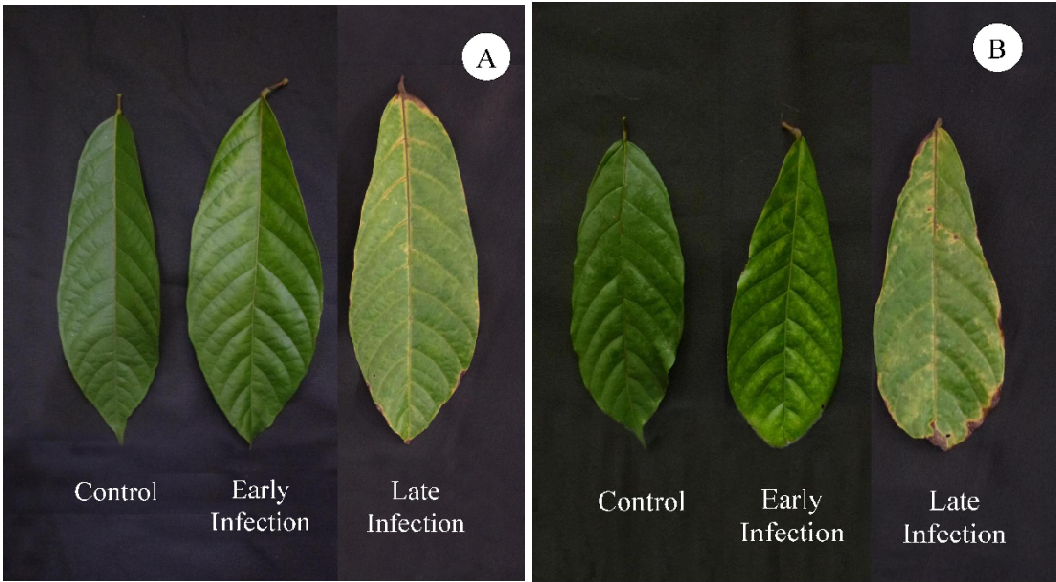

Figure 1. Morphological symptom on VSD-susceptible clone of TSH 858 (A) and VSD-resistant clone of Sca 6 (B) at the three infection stages of $C$. theobromae
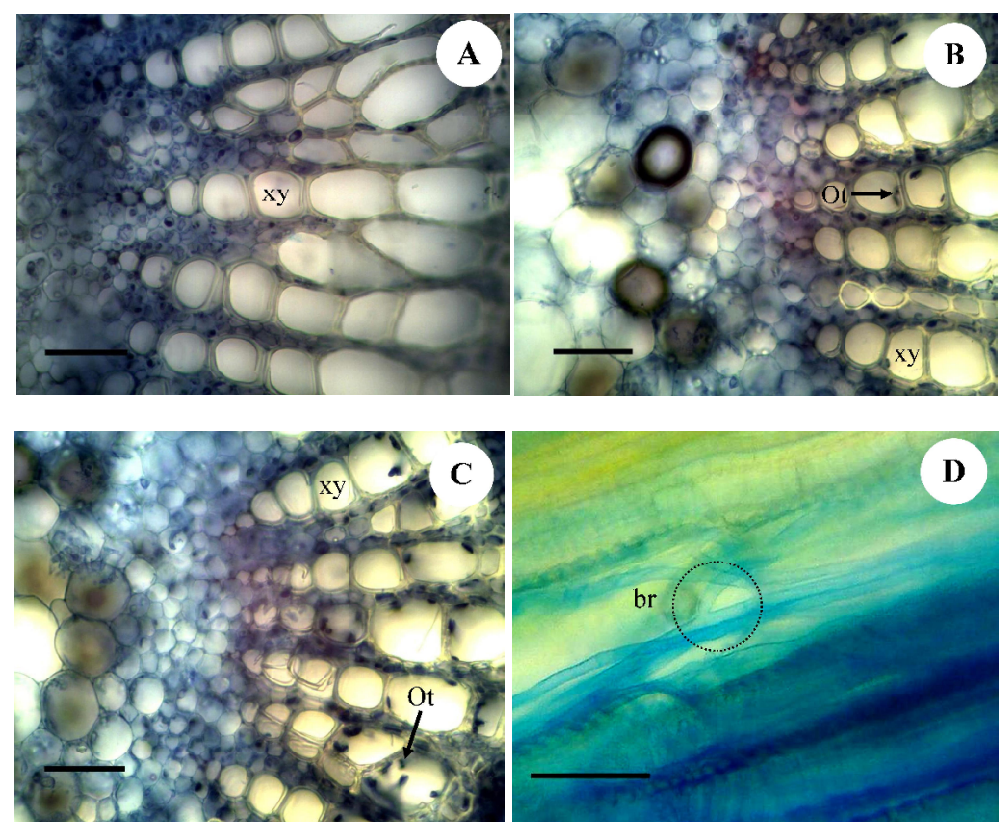

Figure 2. Fungal staining by trypan blue for detection of $C$. theobromae presence. Midrib cross-sections at pre-infection stage (A), early infection stage (B), and late infection stage (C). Midrib longitudinal section: typical branching of $C$. theobromae hyphae at right angles $(\mathrm{D})(\mathrm{xy}=\mathrm{xylem}, \mathrm{Ot}=C$. theobromae hyphae, $\mathrm{br}=$ hyphae typical branching). Scale bars $=50 \mu \mathrm{m}(\mathrm{A}-\mathrm{C}) ; 30 \mu \mathrm{m}(\mathrm{D})$ 
stage (Table 1). There was then an increase in production of I-limonene (a terpenoid compound) and p-ethylguaiacol (a phenolic compound) in both clones at the early stage of $C$. theobromae infection, and again, there was no significant difference between the VSD-resistant and VSD-susceptible clones (Table 1). However, at the late infection stage, production of I-limonene, p-ethylguaiacol, and 2,3 dihidrobenzofuran (terpenoids), were significantly higher in resistant clones than in susceptible clones (Table 1).

Early infection defined as the first time C. theobormae hyphae detected in the xylem vessel of infected leaf, but VSD symptoms not yet appear. Early infection occurred in week $14^{\text {th }}$ (TSH 858) and week $18^{\text {th }}$ (Sca 6) following placement of cacao seedlings under VSD-infected cacao plants. Control was cacao seedlings of the same age, placed outside area of infected cacao plants.

Late infection is defined as when both C. theobormae and VSD symptom have been detected. Late infection in TSH 858 and Sca 6 occurred at $15^{\text {th }}$ and $19^{\text {th }}$ weeks respectively, after cacao seedlings placed under VSD infected cacao plants. Control was cacao seedlings of the same age placed outside area of infected cacao plants.

In the early stage of $C$. theobromae infection there was increasing production of I-limonene and p-ethylguaiacol in both VSD-resistant and VSD-susceptible clones, with no significant difference between the two types of clone at this stage (Table 1). This might be due to similar basic responses of both VSD-resistant and VSD-susceptible cells to the infection, and similar rates of phytoalexin formation (Kuc, 1992). Increased production of I-limonene and p-ethylguaiacol, as well as 2,3 dihidrobenzofuran, occured more significantly in the VSD-resistant clones at the late infection stage (Table 1). It is suggested that I-limonene, p-ethylguaiacol and 2,3 dihidrobenzofuran could be considered as indicators of a triggered defense signaling mechanism, and are produced by host plants induced by $C$. theobromae, mainly in late infection stage. I-limonene, p-ethylguaiacol, and 2,3 dihydrobenzofuran were synthesized during $C$. theobromae infection stages through different metabolite pathways. I-limonene is a monoterpenoid that is synthesized through methyl erythritol phosphate (MEP) in the terpenoid backbone metabolism.

Limonene has been reported as a monoterpenoid that exhibits an antifungal action that is similar to the commercial fungicide, carbendazim. Limonene and carbendazim have been tested against Rhizoctonia solani, Fusarium oxysporum, Penicillium digitatum and Aspergilus niger (Marei et al., 2012). Fungi produce a cellulase enzyme that can degrade cell walls during pathogenesis (Milling \& Richardson, 1995), and it was reported that limonene has a strong inhibitory effect, similar to that of commercial fungicides, on cellulase activity (Marei et al., 2012).

Monoterpenoid is a type of metabolite product synthesized in large quantities through a signal transduction pathway, as a result of jasmonic acid activity (KEGG, 2015). Jasmonic acid is a signal molecule that induces a signal transduction pathway, which leads to the production of phytoalexins as part of the resistance mechanism of Glycine max, in response to Rhizoctonia solani infection (Aliferis et al., 2014).

Phenolic compound p-ethylguaiacol is synthesized through phenylpropanoid pathways. Secretion of the compound from plants is induced by wounds and is involved in the communication and defense systems during Agrobacterium and Rhizobium infection (Bhattacharya et al., 2010). Accumulation of phenolic compounds associated with a hypersensitive response by a plant to pathogen infection has been found in coffee plant 


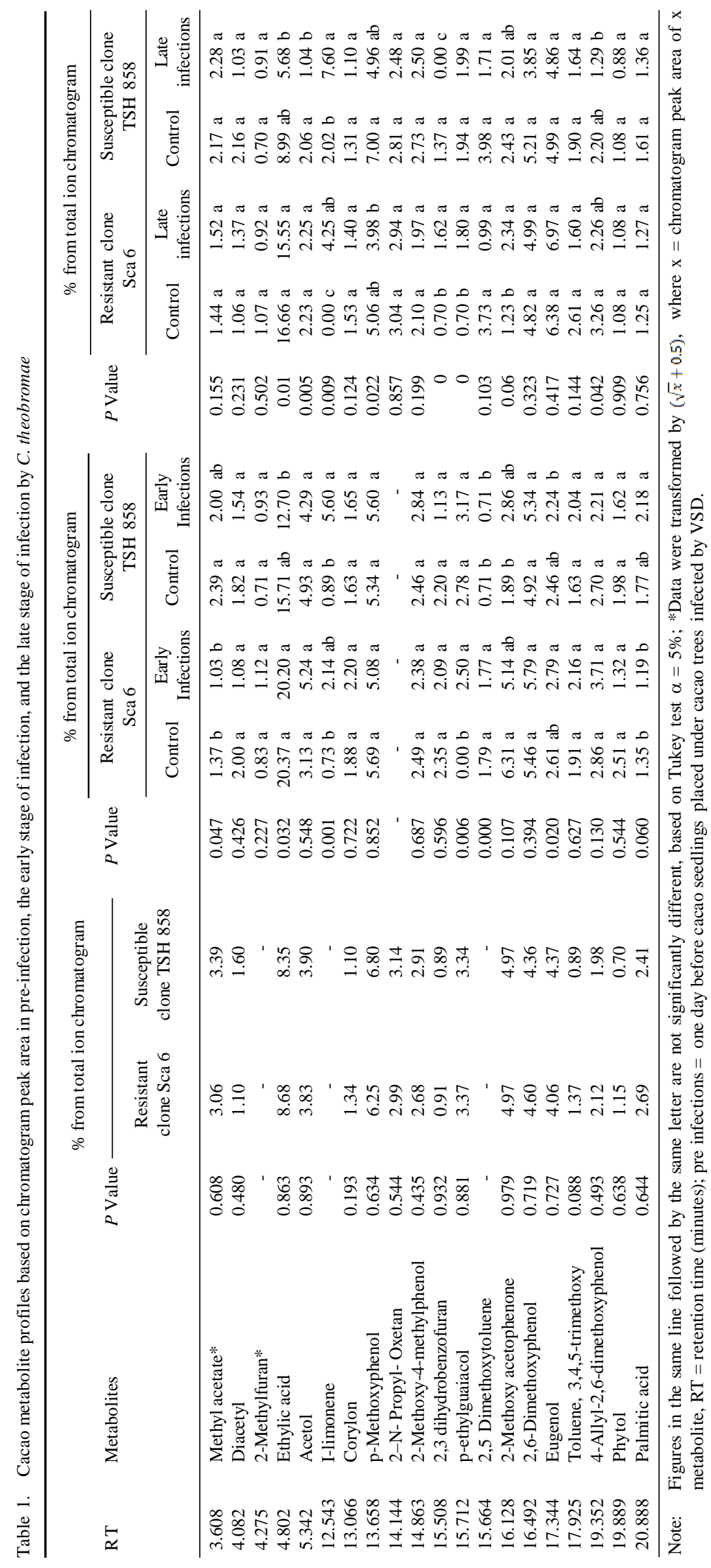


defense mechanism against Colletotrichum kahawae (Loureiro et al., 2012).

2,3-dihydrobenzofuran is a heterocyclic compound that is synthesized through degradation of certain aromatic compounds (KEGG, 2015). Asperfuran is an example of an antifungal 2,3 dihydrobenzofuran produced by a strain of Aspergillus oryzae. Asperfuran inhibits chitin synthase produced by Coprinus cinereus (Pfefferle et al., 1990). Chitin is a major component of fungal cell walls, which play a vital role in hyphal tip growth and fungal morphogenesis. Chitin is synthesized by chitin synthase and it is well known that the latter is inhibited by commercial fungicides (Kong et al., 2012). The 2,3 dihydrobenzofuran compound has also been reported to be produced by Bauhenia purpurea and shows antifungal activity against Candida albicans (Abyaneh \& Rai, 2013).

Role of terpenoid and phenolic compounds in cacao resistance mechanism to pathogens have been reported as phytoalexins in respect of Verticillium dahlia infection. Production of triterpenoid arjunolic acid and the phenolic compounds 3,4 dihydroxyacetophenone and 4-hydroxyaceto-phenone, significantly increases in cacao infected by Verticillium dahlia (Resende et al., 1996). In addition to these terpenoid and phenolic phytoalexins, elemental sulphur is produced as an antifungal substance, in cacao during Verticillium dahlia infection (Cooper \& Williams, 2004; Resende et al., 1996).

\section{Metabolite Accumulation Sites}

Metabolite accumulation sites were found in healthy leaves of both VSD-resistant and VSD-susceptible clones at pre-infection stage. Both clones had leaf laminae consisting of single-layered epidermis tissue with idioblast cells containing phenolic and terpenoid compounds in the upper and lower epidermises
(Figures 3B \& 3D). Phenolic compounds were also detected in palisade tissue (Figure 3A). Glandular trichomes containing phenolic and terpenoid compounds were distributed across both cacao leaf surfaces, although mainly on the leaf midrib (Figures 3C \& 3E). Phenolic compounds also appeared in numerous idioblast cells in the cortex of the midrib (Figures 4A, 4B, \& 4C).

Similar accumulation sites were found in the leaves of VSD-resistant and VSDsusceptible clones during the infection stages of $O$. theobromae. Histochemical staining showed that phenolic and terpenoid content of the phloem in VSD-resistant clones was higher than that of susceptible clones. This was indicated by increasing intensity of dark brown color of the phloem at the time of infection (Figure 5, Table 4).

The secretion of terpenoid and phenolic compounds during $C$. theobromae infection involves phloem tissues. The role of phloem in the secretion of phenolic compounds has been reported in the case of Picea abies infected by Ophiostoma polonicum (Brignolas et al., 2007). It is understandable that phenolic and terpenoid contents in the phloem of VSD-resistant clones were higher than in susceptible clones. This might be related to the secretion of the compounds during the infection stage. Cacao leaves have glandular and non-glandular trichomes (Nakayama et al., 1996). In some plants, glandular trichomes have a role as physical and chemical barriers to spores (Martin \& Clover, 2007; Chattopadyay et al., 2011). However, there is lack of study findings regarding the metabolite content of cacao glandular trichomes. This research showed that glandular trichomes of cacao, containing phenolic and terpenoid compounds, were distributed on both surfaces of cacao leaves, mainly on the leaf midribs. However, the trichomes were generally more abundant on the abaxial than on the adaxial 
leaf surface. Cacao glandular trichomes are of the multiseriate capitate type: composed of a basal cell, two-cell uniseriates and eight cells making up the secretory head. The distribution of glandular trichomes on both VSD- resistant (Sca 6) and VSD-susceptible clones (TSH 858) did not differ statistically, suggesting that the glandular trichome is not closely related to cacao resistance mechanisms to VSD.

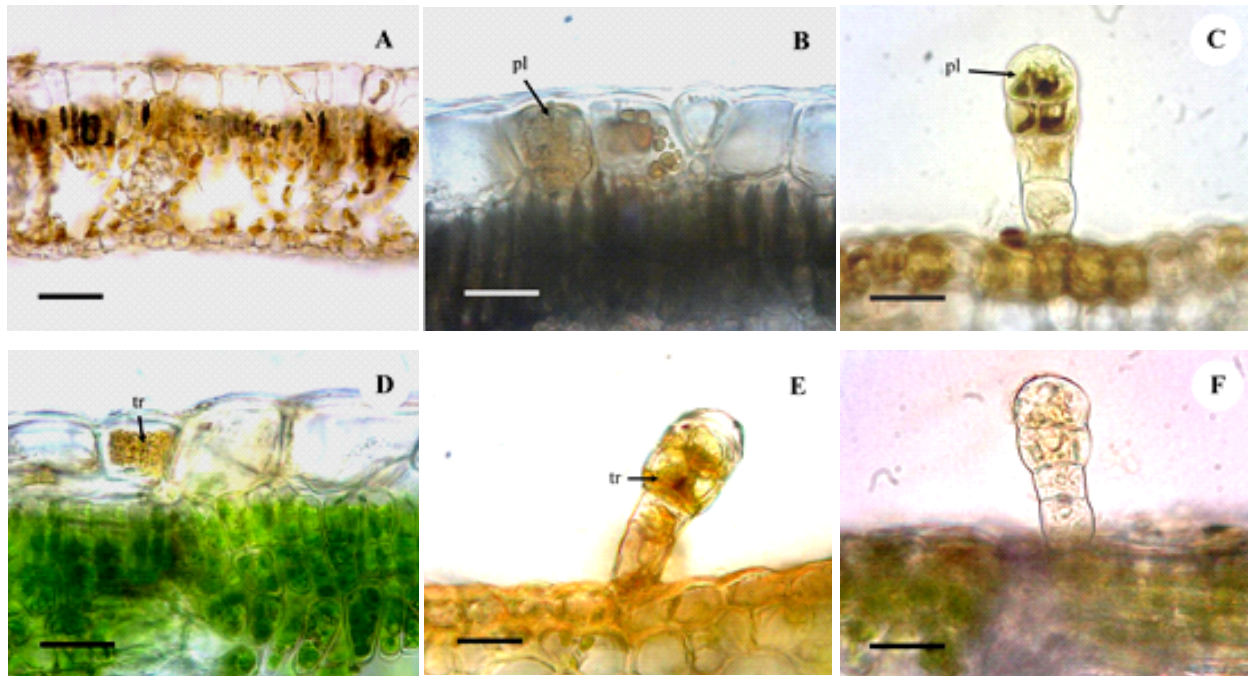

Figure 3. Histochemical staining of cacao leaves. Phenolic compounds detected in palisade tissue (A), idioblast epidermis (B) and glandular trichomes (C). Terpenoids compounds detected in idioblast epidermis (D) and glandular trichomes (E). Glandular trichomes in water as control $(\mathrm{F}) .(\mathrm{pl}=$ phenolic compounds, tr $=$ terpenoids). Scale bar: $50 \mu \mathrm{m}(\mathrm{A}), 20 \mu \mathrm{m}(\mathrm{B}-\mathrm{F})$

Tabel 2. Secondary metabolite production sites during $O$. theobromae infection, based on histochemical staining

\begin{tabular}{|c|c|c|c|c|c|c|c|c|c|c|c|c|}
\hline \multirow{3}{*}{ Cell/tissue } & \multicolumn{4}{|c|}{ Pre infection } & \multicolumn{4}{|c|}{ Early infection } & \multicolumn{4}{|c|}{ Late infection } \\
\hline & \multicolumn{2}{|c|}{ Sca 6} & \multicolumn{2}{|c|}{ TSH 858} & \multicolumn{2}{|c|}{ Sca 6} & \multicolumn{2}{|c|}{ TSH 858} & \multicolumn{2}{|c|}{ Sca 6} & \multicolumn{2}{|c|}{ TSH 858} \\
\hline & $\mathrm{P}$ & $\mathrm{T}$ & $\mathrm{P}$ & $\mathrm{T}$ & $\mathrm{P}$ & $\mathrm{T}$ & $\mathrm{P}$ & $\mathrm{T}$ & $\mathrm{P}$ & $\mathrm{T}$ & $\mathrm{P}$ & $\mathrm{T}$ \\
\hline Glandular trichomes & + & + & + & + & + & + & + & + & $(+)$ & $(+)$ & $(+)$ & $(+)$ \\
\hline Idioblast of upper epidermis & + & + & + & + & + & + & + & + & + & + & + & + \\
\hline Idioblast of lower epidermis & + & + & + & + & + & + & + & + & + & + & + & + \\
\hline Palisade tissue & + & - & + & - & + & - & + & - & + & - & + & - \\
\hline Phloem vessels & ++ & + & ++ & + & +++ & +++ & + & ++ & +++ & +++ & ++ & +++ \\
\hline Idioblast of cortex & + & + & + & + & + & + & + & + & + & + & + & + \\
\hline
\end{tabular}

Note: $\mathrm{P}=$ phenolic compounds; $\mathrm{T}=$ terpenoids; $-=$ not detected,$+=$ fairly detected,$++=$ moderately detected, $+++=$ strongly detected; $(+)=$ lysis. 


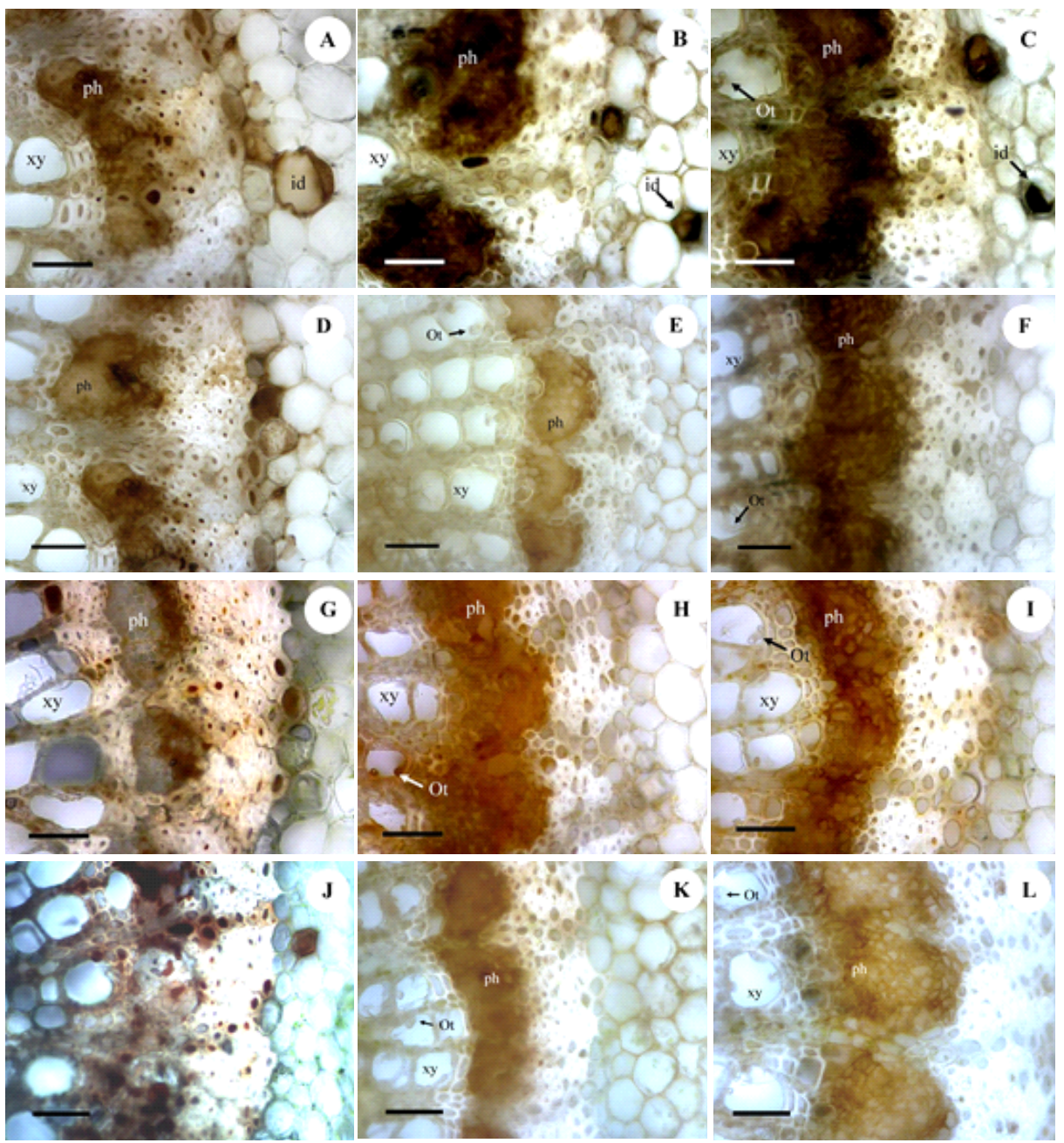

Figure 4. Histochemical staining of phenolic compounds (A-F) and terpenoids (G-L) in cacao leaf midrib of Sca 6 (A-C and G-I) and TSH 858 (D-F and J-L) showing positive results in phloem during pre-infection $(\mathrm{A}, \mathrm{D}, \mathrm{G}, \mathrm{J})$, early infection $(\mathrm{B}, \mathrm{E}, \mathrm{H}, \mathrm{K})$ and late infection $(\mathrm{C}, \mathrm{F}, \mathrm{I}, \mathrm{L}) .(\mathrm{xy}=$ xylem; ph $=$ phloem; id $=$ idioblast; $\mathrm{Ot}=O$. theobromae hyphae). Scale bar: $50 \mu \mathrm{m}(\mathrm{A}-\mathrm{L})$ 


\section{Epidermis as a Barrier}

The leaf epidermis tissue of VSD-resistant clones was significantly thicker than that of susceptible clones, for both leaf surfaces (Table 3). However, size and density of stomata, as well as the distribution of glandular trichomes, were not significantly different between VSD-resistant and VSD-susceptible clones. Interestingly, stomatal pores on the VSDsusceptible clones were found to be wider than those of resistant clones.

Pathogenesis caused by infectious agents begins when the pathogen contacts host plants. Certain anatomical characteristics of leaves can act as physical barriers to pathogens penetrating a host plant. Most pathogens gain access to the plant interior through natural openings such as stomata (Agrios, 1988).

The VSD-resistant and VSD-susceptible clones were not significantly different in terms of stomatal density, length and width. The study suggested that these stomatal characteristics were not directly related to cacao resistance mechanisms to VSD. This finding differs from a previous study that reported a positive association between stomatal density and cacao resistance to VSD (Susilo \& AnitaSari, 2009). However, our research found that the stomatal pores of susceptible clones were wider than those of resistant clones. We suspect that pathogens have more opportunities to penetrate susceptible than resistant plants through the former wider stomatal openings.

A previous study explained that hyphae penetrated young leaves by growing directly through cuticle layers into mesophyll tissues (Prior, 1979). This study found that cacao leaves have a very thin cuticle layer, even on the leaves of resistant clones. Our result offers the possible explanation that physical and biochemical resistance mechanisms to VSD infection may involve leaf epidermis tissue characteristics. The leaf epidermal tissue, on upper and lower surfaces, of resistant clones was significantly thicker than that of susceptible clones on both surfaces. In addition, our results also confirmed that phenolic and terpenoid compounds accumulated on both surfaces of the leaf epidermis. Phenolic compounds that accumulated in the idioblast of epidermis tissue may be involved in biological interaction between cacao and pathogens. Epidermis tissue plays a role in the penetration by pathogens of the host plant through cell wall degradation (Agrios, 1988). Therefore, we propose that epidermis characteristics and the compounds accumulated in the epidermis, be considered as anatomical and biochemical markers of cacao resistance to VSD.

Table 3. Anatomical characters of the leaves of Theobroma cacao clones Sca 6 and TSH 858

\begin{tabular}{|c|c|c|c|}
\hline \multirow{2}{*}{ Anatomical characteristics } & \multirow{2}{*}{ P Value } & \multicolumn{2}{|c|}{ Cocoa clone } \\
\hline & & Sca 6 & TSH 858 \\
\hline Upper epidermis thickness, $\mu \mathrm{m}$ & 0.000 & $22.616 \mathrm{a}$ & $16.953 \mathrm{~b}$ \\
\hline Lower epidermis thickness, $\mu \mathrm{m}$ & 0.000 & $10.448 \mathrm{a}$ & $8.679 \mathrm{~b}$ \\
\hline Palisade tissue thickness, $\mu \mathrm{m}$ & 0.000 & $22.335 \mathrm{~b}$ & $27.018 \mathrm{a}$ \\
\hline Density of adaxial glandular trichomes, $\mathrm{mm}^{-2}$ & 0.271 & $1.897 \mathrm{a}$ & $1.743 \mathrm{a}$ \\
\hline Density of abaxial glandular trichomes, $\mathrm{mm}^{-2}$ & 0.278 & $5.282 \mathrm{a}$ & $4.974 \mathrm{a}$ \\
\hline Length of glandular trichomes head, $\mu \mathrm{m}$ & 0.314 & $28.705 \mathrm{a}$ & $32.688 \mathrm{a}$ \\
\hline Width of glandular trichomes head, $\mu \mathrm{m}$ & 0.308 & $26.700 \mathrm{a}$ & $29.057 \mathrm{a}$ \\
\hline Stomatal density, $\mathrm{mm}^{-2}$ & 0.184 & $1138.5 \mathrm{a}$ & $1076.9 \mathrm{a}$ \\
\hline Stomatal index & 0.007 & $14.842 \mathrm{a}$ & $13.380 \mathrm{~b}$ \\
\hline Length of stomata, $\mu \mathrm{m}$ & 0.063 & $12.410 \mathrm{a}$ & $12.730 \mathrm{a}$ \\
\hline Width of stomata, $\mu \mathrm{m}$ & 0.083 & $13.764 \mathrm{a}$ & $14.120 \mathrm{a}$ \\
\hline Length of stomatal pore, $\mu \mathrm{m}$ & 0.000 & $4.950 \mathrm{~b}$ & $5.972 \mathrm{a}$ \\
\hline
\end{tabular}

Note: ${ }^{*}$ Number in the same row followed by the same letter are not significantly different, based on T-test $\alpha=5 \%$. 


\section{CONCLUSIONS}

I-limonene, p-ethylguaiacol and 2,3 dihidrobenzofuran may act as potential phytoalexins produced by the host after infected by pathogen mainly on the late infection of C. theobromae. Terpenoid and phenol compounds were accumulated on idioblast of upper and bottom epidermis of cacao leaves. Epidermis thickness of resistant clone was significantly greater than that of susceptible clone on both surfaces. Leaf epidermis tissue and the accumulated compounds in epidermis idioblast are proposed as a physical and biochemical markers of cocoa resistances against VSD disease.

\section{ACKNOWLEDGEMENT}

The authors thank to Director of ICCRI for supporting funding this research through Insinas Research Grant 2015 and also to Ministry of Research, Technology and Higher Education of the Republic of Indonesia.

\section{REFERENCES}

Abyaneh, M.R. \& M. Rai (2013). Antifungal Metabolites from Plants. SpringerVerlag Berlin Heidelberg, New York.

Agrios G.N. (1988). Plant Pathology. $3^{\text {rd }}$ Ed. Academic Press Inc, New York.

Aliferis, K.A.; D. Faubert \& S. Jabaji (2014). A metabolic profiling strategy for the dissection of plant defense against fungal pathogens. Plos One. 9, 1-13.

Bhattacharya, A.; P. Sood \& V. Citovsky (2010). The roles of plant phenolic in defense and communication during Agrobacterium and Rhizobium infection. Molecular Plant Pathology, 11, 705-19.

Brignolas, F.; F. Lieutier; D. Sauvard; A. Yart; A. Drouet \& A. Claudot (2007). Changes in soluble phenol content of Norway spruce (Picea abies) phloem in response to wounding an inocula- tion with Ophiostoma polonicum. Forest Pathology, 25, 253-265.

Chattopadhyay, S.; K.A. Ali; S.G. Dos; N.K. Das; R.K. Agarwal; T.K. Bandopadhyay; A. Sarkar \& Bajpai (2011). Association of leaf micro-morphological characters with powdery mildew resistance in field-grown mulberry (Morus spp.) germplasm. AoB / PLANTS, 1-11.

Chaves, F.B. \& T.J. Gianfagna (2007). Necrotrophic phase of Moniliophtora perniciosa causes salicylic acid accumulation in infected stem of cacao. Physiological Molecular Plant Pathology, 69, 104-108.

Cooper, R.M. \& J.S. Williams (2004). Elemental sulphur as an induced antifungal substance in plant defense. Journal of Experimental Botany, 55, 1947-1953.

Dennis, J.J.C. (1991). Epidemiology and Control of Vascular Streak Dieback of Cacao in Papua New Guinea. MSc thesis. La Trobe University, Australia.

Guest, D. \& P.J. Keane (2007). Vascular streak dieback: A new encounter disease of cacao in Papua New Guinea and Southeast Asia caused by the obligate Basidiomycete Ceratobasidium theobromae. American Phytopathology Society, 97, 1654-1657.

Halimah, D. \& S. Sukamto (2007). Vascular streak dieback intensity on some clones of Indonesian coffee and cacao collection. Pelita Perkebunan, 23, 118-128.

Harborne, J.B. (1987). Metode Fitokimia Penuntun Cara Modern Menganalisis Tumbuhan. (Translated: K. Padmawinata; I. Soediro; \& S. Niksolihin). Institut Teknologi Bandung Press, Bandung.

ICCO (2014). Quarterly Bulletin of Cacao Statistics (Cacao year 2013/2014). International Cocoa Organization. London.

Johansen, D.A. (1940). Plant Microtechnique. McGraw-Hill. New York.

Junianto, Y.D. \& Sri-Sukamto (1986). Vascular streak dieback pada tanaman kakao di 
Jawa Timur : isolasi dan identifikasi jamur penyebab penyakit. Pelita Perkebunan, 2, 25-28.

Keane, P.J. \& C. Prior (1991). Vascular streak dieback of cacao. Journal Plant Pathology, 33, 135-139.

KEGG (2015). The Kyoto Ecyclopedia Genes and Genome. http://www.genome.jp/kegg/

Kong, L.A.; J. Yang; G. Li; L.L. Qi; Y.J. Zhang \& C.F. Wang (2012). Different chitin synthase genes are required for various developmental and plant infection processes in the rice blast fungus Magnaporthe oryzae. Journal of Pathogenesis, 8, 1 - 16.

Kuc, J. (1992). Antifungal compounds from plants. p. 159-184. In: H.N. Nigg \& D. Seigler (Eds). Phytochemical Resources for Medicine and Agriculture. Plenum Press. New York.

Lam, C.H.; G. Verghese \& M.A.Z. Abidin (1988). In vitro production of Oncobasidium theobromae basidiospores. British Mycology Society, 90, 505-507.

Liberato, J.R.; R.W. Barreto \& R.G. Shivas (2005). Leaf-clearing and staining techniques for the observation of conidiophores in the Phyllactinioideae (Erysiphaceae). Australian Plant Pathology, 34, 401-404.

Loureiro A.; M.R. Nicole; V. Varzea; P. Moncada; B. Bertrand \& M.C. Silva (2012). Coffee resistance to Colletotrichum kahawae is associated with lignifications, accumulation of phenols and cell death at infection sites. Physiological and Molecular Plant Pathology, 77, 23-32.

Marei G.I.K.; M.A.A. Rasoul \& S.A.M. Abdelgaleil (2012). Comparative antifungal activities and biochemical effect of monoterpenes on plant pathogenic fungi. Pesticide Biochemistry and Physiology, 103, 56-61.

Martin, C. \& B.J. Glover (2007). Functional aspect of cell pattern in aerial epidermis. Current Opinion in Plant Biology, 10, 70-78.
McMahon, P.; A. Purwantara; A.W. Susilo; S. Sukamto; A. Wahab; H.B. Purung \& M. Hidayat (2010). On-farm selection for quality and resistance to pest/ disease of cocoa in Sulawesi: (ii) quality and performance of selections against Phytophthora pod rot and vascular streak dieback. International Journal of Pest Management, 56, 351-361.

Milling, R.J. \& C.J. Richardson (1995). Mode of action of the aniline pyrimidine fungicide primethanil 2. Effect on enzyme secretion in Botrytis cinerea. Pest Science, 45, 43-48.

Nakayama, L.H.I.; M.K.M. Soares \& A.B. Gloria (1996). Contribuicao ao estudo anatomico da folha e do caule do cacaueiro (Theobroma cacao). Scientia Agricola, 53, 73-78.

Pfefferle, W.; H. Anke; M. Bross; B. Steffan; R. Vianden \& W. Steglich (1990). Asperfuran a novel antifungal metabolite from Aspergillus oryzae. Journal Antibiotics, 43, 648-54.

Prior, C. (1979). Resistance of cocoa to vascularstreak dieback disease. Annals of Applied Biology, 92, 369-376.

Resende, M.L.V; J. Flood; J.D. Ramsden; M.G. Rowan; M.H. Baele \& R.M. Cooper (1996). Novel phytoalexin including elemental sulphur in the resistance of cacao (Theobroma cacao L) to Verticillium wilt (Verticillium dahlia Kleb). Physiological and Molecular Plant Pathology, 48, 347-359.

Talbot, P.H.B. \& P.J. Keane (1971). Oncobasidium: A new genus of tulasnelloid fungi. Australian Journal Botany, 19, 203-206.

Taiz, L. \& E. Zeiger (2010). Plant Physiology. $5^{\text {th }}$ Ed. Sinauer Associates Inc, Sunderland.

Samuel, G.J.; A. Ismaiel; A. Rosmana; M. Junaid; D. Guest; P. McMahon; P.J. Keane; A. Purwantara; S.Lambert \& C.M. Rodriguez (2012). Vascular streak dieback of cacao in Southeast Asia and Melanesia: 
in planta detection of the pathogen and a new taxonomy. Fungal Biology, $116,11-23$

Sass, J.E. (1951). Botanical Microtechnique. $2^{\text {nd }}$ Ed. The Iowa State College Press, Iowa.
Susilo, A.W. \& Annita-Sari (2009). Respon ketahanan beberapa hibrida kakao (Theobroma cacao L.) terhadap serangan penyakit pembuluh kayu. Pelita Perkebunan, 27, 77-87.

$$
* * 0 * *
$$

